\title{
The best parameters selection using pso algorithm to solving for ito system by new iterative technique
}

\author{
Karam Adel Abed ${ }^{1}$, Abeer Abdulkhaleq Ahmad ${ }^{2}$ \\ ${ }^{1}$ Department operations Research and intelligence techniques, College of Computer Sciences and Mathematics, \\ University of Mosul, Iraq \\ ${ }^{2}$ Department of mathematics, College of Computer Sciences and Mathematics, University of Mosul, Iraq
}

\begin{tabular}{l} 
Article Info \\
\hline Article history: \\
Received Sep 30, 2019 \\
Revised Dec 1, 2019 \\
Accepted Dec 15, 2019 \\
\hline
\end{tabular}

\section{Keywords:}

New iterative method Partial differential equation Pso algorithm

\begin{abstract}
The main aim of this study is to obtain the best approximate solution for the nonlinear Ito system by applying the new iterative method, A new technique has been proposed that combines the new iterative method with the particle optimization algorithm. The most important distinctive of this work is the analysis of errors between the exact solution of the system and the approximate solutions, which showed us that these approximate solutions of the proposed technique in particular have high accuracy because they converge significantly from the exact solution.
\end{abstract}

Copyright $(2020$ Institute of Advanced Engineering and Science. All rights reserved.

\section{Corresponding Author:}

Karam Adel Abed,

Department operations Research and intelligence techniques,

College of Computer Sciences and Mathematics, University of Mosul, Mosul, Iraq.

Email: karamadel@uomosul.edu.iq

\section{INTRODUCTION}

In this paper, we apply the new iterative method of the generalized Ito system in order to obtain the best approximate solutions and then compare them with the exact solutions to reach the required efficiency,

$$
\left\{\begin{array}{c}
\frac{\partial \mathrm{k}}{\partial \mathrm{t}}=\frac{\partial \mathrm{q}}{\partial \mathrm{x}} \\
\frac{\partial \mathrm{q}}{\partial \mathrm{t}}=-2 \frac{\frac{\partial}{3} \mathrm{q}^{3}}{\partial \mathrm{x}^{3}}-\alpha(\mathrm{kq})_{\mathrm{x}}-6(\mathrm{RS})_{\mathrm{x}} \\
\frac{\partial \mathrm{R}}{\partial \mathrm{t}}=\frac{\partial^{3} \mathrm{R}}{\partial \mathrm{x}^{3}}+\delta \mathrm{kR}_{\mathrm{x}} \\
\frac{\partial \mathrm{p}}{\partial \mathrm{t}}=\frac{\partial^{3} \mathrm{~S}}{\partial \mathrm{x}^{3}}+\delta \mathrm{kS}_{\mathrm{x}}
\end{array}\right\}
$$

Where the parameters $\alpha, \delta, \mu, \mathrm{b} 2$ optional constants. the non-linear part has many important features in many physical phenomena. Therefore, the non-linear system of partial differential equations is very effective in many fields, including astronomy, acoustics, mechanical engineering, etc..., The generalized Ito system is partial nonlinear differential equations and can be reduced to normal differential equations by painleve and has applications in mathematical, physical and other phenomena [1].

In orderly to resolve nonlinear problems, numerical methods have been shown and clarified, due to the great significance in various domain of science, especially mathematics and physics. Non-linear problems are studied. In the past decades a group of authors have paid special attention in studying non-linear equations solutions using methods Numerical ones. Among these are Inverse scattering method, Bucklund 
transformations, and the tanh-function method [2]. Obtaining the exact solution of the nonlinear system of partial differential equations has become one of the most important aspects because of its importance in understanding the mechanism of complex phenomena, such as (NSPDE), Literature is the first breakthrough in the nonlinear generalized Ito system proposed in 1980, according to the perception of the world of Ito dual systems [3]. The variational iteration method was applied to the nonlinear generalized Ito system [4]. there are many numerical methods used to solve the generalized Ito system, including:

Jacobian-function technique [5]. Adomian decomposition technique [6]. F-expansion technique [7]. Sine-cosine technique [8]. and other numerical methods the new iterative technology offers a highly efficient approach to controlled solutions and a wide range of differential systems. They are also considered to have a significant advantage over non-linear methods such as Homotopy technique.

The main aim of using the new iterative method proposed by Jafari and Daftardar [9-11], and has been modifed by Hameda [12-14], to resolve the partial and ordinary linear and nonlinear differential equations, and give the importance of equations and their applications in various practical fields and this is the basis on which the application of this method [15-20]. The new iterative method NIM technique is unpretentious to grasp and easy to do on the computer and has very effective results, which gave it a great benefit in resolving a variety of equations including algebraic and integral and partial and normal differential equations with the correct and fractional ranks and systems of equations [21]. The new iterative method NIM is simple to understand and easy to implement on the computer and has very effective results, which gave it a great benefit in solving a variety of equations, including algebraic and integral and partial differential equations and ordinary differential equations with fractional and correct ranks and equation systems [21].

The particle swarm optimaiztion PSO algorithm is widely known for its ease of implementation and its ability to quickly converge to the optimal solution. The particle swarm optimaiztion PSO algorithm also has qualities and features that make it distinctly efficient as it does not require improvement of any scalable information of the function and uses simple logical factors, compared to other algorithms, we find it characterized by its speed, low cost and accuracy [22-24]. The pso algorithm is suitable for solving linear, non-linear, intermittent and continuous variables, so that is has been used as a robust method to solve optimization problems in a wide variety of applications [25-27], We work to reduce the error to a minimum in the numerical method used the new iterative method and thus arrive at the nearest approximate and analytical solution to the exact solution of the system Ito. The following is a flowchart showing the PSO algorithm in Figure 1 [28, 29]:

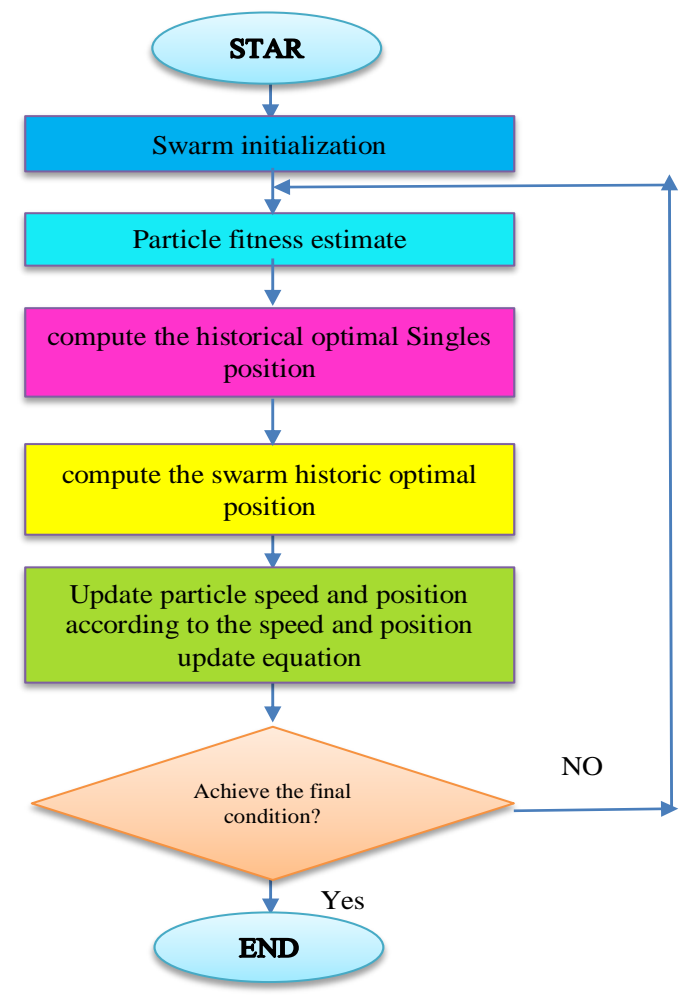

Figure 1. Flowchart showing the PSO algorithm 
In this article we will improve the results and minimize the error so that it converges to the exact solution of the non-linear Ito system by solving the system with the new iterative method and then proposing a new strategy between the new iterative method with the Pso algorithm.

In this paper is organized as follows: 1 . in this section the mathematical model and previous works are presented with a brief introduction to the pso algorithm. 2. in this part Provide the basic idea of the new iterative method. 3. in this section Solve the nonlinear Ito system in the new iterative way. 4. in this section This section is dedicated to illustrating the proposed method of new iterative method with particle swarm optimaiztion (NIM-PSO) 5. in this part we discuss the final observations.

\section{NEW ITERATIVE METHOD (NEM)}

look the next general functional equation:

$\mathrm{k}(\mathrm{y})=\mathrm{f}(\mathrm{y})+\mathrm{C}((\mathrm{y}))$

Here $\mathrm{N}(\mathrm{x})$ is a nonlinear border, we are assuming that $\mathrm{u}$ in (2) having the chain form:

$\mathrm{k}(\mathrm{y})=\sum_{\mathrm{i}=0}^{\infty} \mathrm{k}_{\mathrm{i}}(\mathrm{y})$

That is:

$\mathrm{C}\left(\sum_{\mathrm{i}=0}^{\infty} \mathrm{k}_{\mathrm{i}}(\mathrm{y})=\mathrm{C}\left(\mathrm{k}_{0}(\mathrm{y})+\sum_{\mathrm{i}=0}^{\infty}\left\{\mathrm{C}\left(\sum_{\mathrm{j}=0}^{\mathrm{i}} \mathrm{k}_{\mathrm{j}}(\mathrm{y})\right)-\sum_{\mathrm{j}=0}^{\mathrm{i}-1} \mathrm{k}_{\mathrm{j}}(\mathrm{y})\right\}\right.\right.$

The nonlinear border $N$ can be decomposed as:

$\mathrm{C}\left(\sum_{\mathrm{i}=0}^{\infty} \mathrm{k}_{\mathrm{i}}(\mathrm{y})=\mathrm{f}+\mathrm{C}\left(\mathrm{k}_{0}(\mathrm{y})+\sum_{\mathrm{i}=0}^{\infty}\left\{\mathrm{C}\left(\sum_{\mathrm{j}=0}^{\mathrm{i}} \mathrm{k}_{\mathrm{j}}(\mathrm{y})\right)-\sum_{\mathrm{j}=0}^{\mathrm{i}-1} \mathrm{k}_{\mathrm{j}}(\mathrm{y})\right\}\right.\right.$

by utilize the (4) and (5) in (2):

$$
\begin{aligned}
& \mathrm{k}_{1}(\mathrm{y}, \mathrm{t})=\mathrm{C}\left(\mathrm{k}_{0}(\mathrm{y}, \mathrm{t})\right) \\
& \mathrm{k}_{2}(\mathrm{y}, \mathrm{t})=\mathrm{C}\left(\mathrm{k}_{0}(\mathrm{y}, \mathrm{t})+\mathrm{k}_{1}(\mathrm{y}, \mathrm{t})-\mathrm{C}\left(\mathrm{k}_{0}(\mathrm{y}, \mathrm{t})\right)\right) \\
& \mathrm{k}_{3}(\mathrm{y}, \mathrm{t})=C\left(\mathrm{k}_{0}(\mathrm{y}, \mathrm{t})+\mathrm{k}_{1}(\mathrm{y}, \mathrm{t})+\mathrm{k}_{2}(\mathrm{y}, \mathrm{t})-\mathrm{C}\left(\mathrm{k}_{0}(\mathrm{y}, \mathrm{t})+\mathrm{k}_{1}(\mathrm{y}, \mathrm{t})\right)\right) \\
& \mathrm{k}_{\mathrm{n}+1}(\mathrm{y}, \mathrm{t})=C\left(\mathrm{k}_{0}(\mathrm{y}, \mathrm{t})+\mathrm{k}_{1}(\mathrm{y}, \mathrm{t})+\cdots+\mathrm{k}_{\mathrm{n}}(\mathrm{y}, \mathrm{t})-\mathrm{C}\left(\mathrm{k}_{0}(\mathrm{y}, \mathrm{t})+\mathrm{k}_{1}(\mathrm{y}, \mathrm{t}) \cdots+\mathrm{k}_{\mathrm{n}-1}(\mathrm{y}, \mathrm{t})\right)\right) ; \mathrm{n}=
\end{aligned}
$$

We realize the iterate relation in the next method:

$$
\sum_{\mathrm{i}=0}^{\infty} \mathrm{k}_{\mathrm{i}}(\mathrm{y})=\mathrm{f}+\mathrm{C}\left(\sum_{\mathrm{j}=0}^{\infty} \mathrm{k}_{\mathrm{j}}(\mathrm{y})\right.
$$

The $\mathrm{n}$-terms solutions of (1) is given by $\mathrm{k} \approx \mathrm{k}_{0}+\mathrm{k}_{1}+\mathrm{k}_{2}+\mathrm{k}_{3}+\cdots \cdots+\mathrm{k}_{\mathrm{n}-1}$. The convergence of this method given in [19].

\section{APPLICATION ITO COUPLED SYSTEM:}

In this partition, we work on for solving $k(y, t), Q(y, t), R(y, t)$ and $S(y, t)$ the initial conditions [4] which suitable (1):

$$
\left\{\begin{array}{l}
\mathrm{k}(\mathrm{y}, 0)=\mathrm{r}_{1}-2 \mu^{2} \tanh ^{2}(\mu \mathrm{x}) \\
\mathrm{Q}(\mathrm{y}, 0)=\mathrm{r}_{2}+\mathrm{b}_{2} \tanh ^{2}(\mu \mathrm{x}) \\
\mathrm{R}(\mathrm{y}, 0)=\mathrm{r}_{3}+\mathrm{f}_{1} \tanh (\mu \mathrm{x}) \\
\mathrm{S}(\mathrm{y}, 0)=\mathrm{t}_{0}+\mathrm{t}_{1} \tanh (\mu \mathrm{x})
\end{array}\right\}
$$


we build in the new coupled ito system (1) which satisfy:

$$
\left\{\begin{array}{c}
C(k, Q, R, S)=\frac{\partial Q}{\partial x} \\
B(k, Q, R, S)=-2 \frac{\partial^{3} Q}{\partial x^{3}}-6(k q)_{x}-6(R S)_{x} \\
L(k, Q, R, S)=\frac{\partial^{3} R}{\partial x^{3}}+3 k R_{x} \\
Y(k, Q, R, S)=\frac{\partial^{3} p}{\partial x^{3}}+3 k S_{x}
\end{array}\right\}
$$

Through the integration of the Ito system we get the following:

$$
\left\{\begin{array}{c}
k(y, t)=\int_{0}^{t} C(k(y, t), Q(y, t), R(y, t), S(y, t)) d t=\int_{0}^{t}\left(\frac{\partial Q}{\partial x}\right) d t \\
q(x, t)=\int_{0}^{t} B(k(y, t), q(y, t), R(y, t), S(y, t)) d t=\int_{0}^{t}\left(-2 \frac{\partial^{3} Q}{\partial x^{3}}-6(k Q)_{x}-6(R S)_{x}\right) d t \\
w(x, t)=\int_{0}^{t} L(k(y, t), Q(y, t), R(y, t), S(y, t)) d t=\int_{0}^{t}\left(\frac{\partial^{3} R}{\partial x^{3}}+3 k R_{x}\right) d t \\
S(x, t)=\int_{0}^{t} K(k(y, t), v(y, t), R(y, t), S(y, t)) d t=\int_{0}^{t}\left(\frac{\partial^{3} S}{\partial x^{3}}+3 k S_{x}\right) d t
\end{array}\right\}
$$

Using the initial conditions given, we have:

$\mathrm{k}_{1}(\mathrm{y}, \mathrm{t})=\int_{0}^{\mathrm{t}} \mathrm{N}\left(\mathrm{k}_{0}, \mathrm{Q}, \mathrm{R}_{0}, \mathrm{~S}_{0}\right) \mathrm{dt}=\int_{0}^{\mathrm{t}}\left(\frac{\partial \mathrm{Q}}{\partial \mathrm{x}}\right) \mathrm{dt}$

and from integral equation we obtain:

$\mathrm{k}_{1}(\mathrm{x}, \mathrm{t})=\frac{0.5 \sinh (0.5 \mathrm{x}) \mathrm{t}}{\cosh (0.5 \mathrm{x})^{3}}$

Now,

$Q_{1}(y, t)=\int_{0}^{t} M\left(k_{0}, Q_{0}, R_{0}, S_{0}\right) d t=\int_{0}^{t}\left(-2 \frac{\partial^{3} Q}{\partial x^{3}}-6(k Q)_{x}-6(R S)_{x}\right) d t$

$\mathrm{Q}_{1}(\mathrm{y}, \mathrm{t})=\frac{1}{\cosh (0.5 \mathrm{x})^{6}}(0.5 \sinh (0.5 \mathrm{x}) \cdots \cdots+3 * \sinh (0.5 \mathrm{x}) \mathrm{t}$

Also,

$\mathrm{R}_{1}(\mathrm{y}, \mathrm{t})=\int_{0}^{\mathrm{t}} \mathrm{L}\left(\mathrm{k}_{0}, \mathrm{Q}_{0}, \mathrm{R}_{0}, \mathrm{~S}_{0}\right) \mathrm{dt}=\int_{0}^{\mathrm{t}}\left(\frac{\partial^{3} \mathrm{R}}{\partial \mathrm{x}^{3}}+3 \mathrm{kR} \mathrm{R}_{\mathrm{x}}\right) \mathrm{dt}$

$\mathrm{R}_{1}(\mathrm{y}, \mathrm{t})=-\frac{0.5 \mathrm{t}}{\cosh (0.5 \mathrm{x})^{2}}$

And finally:

$S_{1}(y, t)=\int_{0}^{t} K\left(k_{0}, Q, R_{0}, S_{0}\right) d t=\int_{0}^{t}\left(\frac{\partial^{3} S}{\partial x^{3}}+3 k S_{x}\right) d t$

$S_{1}(y, t)=-\frac{0.5 t}{\cosh (0.5 x)^{2}}$

the repetition rapport (6) from integral the system (1) is:

$\mathrm{k}_{2}(\mathrm{y}, \mathrm{t})=\int_{0}^{\mathrm{t}}\left(\mathrm{C}\left(\mathrm{k}_{0}(\mathrm{y}, \mathrm{t})+\mathrm{k}_{1}(\mathrm{y}, \mathrm{t}), \mathrm{Q}_{0}(\mathrm{y}, \mathrm{t})+\mathrm{Q}_{1}(\mathrm{y}, \mathrm{t}), \mathrm{R}_{0}(\mathrm{y}, \mathrm{t})+\mathrm{R}_{1}(\mathrm{y}, \mathrm{t}), \mathrm{S}_{0}(\mathrm{y}, \mathrm{t})+\mathrm{S}_{1}(\mathrm{y}, \mathrm{t})\right)\right) d \mathrm{t}$

Then,

$\mathrm{k}_{1}(\mathrm{y}, \mathrm{t})=-\frac{45}{23658496} * \frac{1}{\cosh (\mathrm{x}+10)^{15}} \cdots+\cosh (\mathrm{x}+10)^{4} \sqrt{209} \sinh (\mathrm{x}+10) 1$

Such that: 
$\mathrm{k}_{2}(\mathrm{y}, \mathrm{t})=\sum_{\mathrm{i}=0}^{\mathrm{n}+1} \mathrm{k}_{\mathrm{i}}(\mathrm{x}, \mathrm{t})=\mathrm{k}_{1}(\mathrm{x}, \mathrm{t})+\mathrm{k}_{2}(\mathrm{x}, \mathrm{t})+\mathrm{k}_{3}(\mathrm{x}, \mathrm{t})+\cdots \cdots+\mathrm{k}_{\mathrm{n}+1}(\mathrm{x}, \mathrm{t})$

And finally:

$\mathrm{k}_{3}(\mathrm{y}, \mathrm{t})=\frac{15}{39180} * \frac{1}{\cosh (\mathrm{x}+10)^{15}} \cdots+\cosh (\mathrm{x}+10)^{20} \sqrt{209} \mathrm{t} * \sinh (\mathrm{x}+10)$

Then,

$\mathrm{k}(\mathrm{y}, \mathrm{t})=\frac{5}{39180} * \frac{1}{\cosh (\mathrm{x}+10)^{31}} \cdots \cdots+\mathrm{t} * \sinh (\mathrm{x}+10) 39180 \ldots \cosh (\mathrm{x}+10)^{31}$

We will follow the same steps above to find the rest of the system term (1):

$$
\begin{aligned}
& \left.\mathrm{Q}(\mathrm{y}, \mathrm{t})=\frac{1}{7680} * \frac{1}{\cosh (8 \mathrm{x})^{20}}\left(1185 \cosh (8 \mathrm{x})^{20}-\cdots \cdots\right)-4114 \mathrm{t}^{4} * \sinh (8 \mathrm{x}) \cosh (8 \mathrm{x})^{5}\right) \\
& \mathrm{R}(\mathrm{y}, \mathrm{t})=\frac{1}{24} * \frac{1}{\cosh (8 \mathrm{x})^{14}}\left(-30 \mathrm{t}^{4} \sinh (8 \mathrm{x}) \cosh (8 \mathrm{x})^{11}+\cdots \cdots+120 * \sinh (8 \mathrm{x}) \cosh (8 \mathrm{x})^{13}\right. \\
& \mathrm{S}(\mathrm{y}, \mathrm{t})=\frac{1}{30} * \frac{1}{\cosh (8 \mathrm{x})^{14}}\left(-30 \mathrm{t}^{2} \sinh (8 \mathrm{x}) \cosh (8 \mathrm{x})^{11}+\cdots \cdots+120 * \sinh (8 \mathrm{x}) \cosh (8 \mathrm{x})^{13}\right.
\end{aligned}
$$

Tables 1, 2 and Figures 2 till 5 respectively show the behavior of numerical solutions obtained from the new iterative method and the PSO algorithm with comparison between them of the space $(x)$ and the time $(\mathrm{t})$ them.

\section{THE PROPOSED TECHNIQUE (NIM-PSO)}

The concept of the proposed technique is based finding the optimal parameters of nonlinear Ito coupled system using the particle swarm optimaiztion PSO with the new iterative method NIM. The result of (NIM) solution series (17)-(18)-(19)-(20) is used to subedit the fitness function in the (PSO) algorithm using the next equations:

$$
\left\{\begin{array}{c}
\mathrm{K}\left(\alpha, \delta, \mu, \mathrm{b}_{2}\right)=\sum_{\mathrm{i}=1}^{\mathrm{n}} \sum_{\mathrm{j}=1}^{\mathrm{m}}\left(\mathrm{k}\left(\mathrm{x}_{\mathrm{i}}, \mathrm{t}_{\mathrm{j}}\right)-\hat{\mathrm{k}}\left(\mathrm{x}_{\mathrm{i}}, \mathrm{t}_{\mathrm{j}}\right)\right)^{2} \\
\mathrm{Q}\left(\alpha, \delta, \mu, \mathrm{b}_{2}\right)=\sum_{\mathrm{i}=1}^{\mathrm{n}} \sum_{\mathrm{j}=1}^{\mathrm{m}}\left(\mathrm{q}\left(\mathrm{x}_{\mathrm{i}}, \mathrm{t}_{\mathrm{j}}\right)-\hat{\mathrm{q}}\left(\mathrm{x}_{\mathrm{i}}, \mathrm{t}_{\mathrm{j}}\right)\right)^{2} \\
\mathrm{R}\left(\alpha, \delta, \mu, \mathrm{b}_{2}\right)=\sum_{\mathrm{i}=1}^{\mathrm{n}} \sum_{\mathrm{j}=1}^{\mathrm{m}}\left(\mathrm{R}\left(\mathrm{x}_{\mathrm{i}}, \mathrm{t}_{\mathrm{j}}\right)-\widehat{\mathrm{R}}\left(\mathrm{x}_{\mathrm{i}}, \mathrm{t}_{\mathrm{j}}\right)\right)^{2} \\
\mathrm{~S}\left(\alpha, \delta, \mu, \mathrm{b}_{2}\right)=\sum_{\mathrm{i}=1}^{\mathrm{n}} \sum_{\mathrm{j}=1}^{\mathrm{m}}\left(\mathrm{S}\left(\mathrm{x}_{\mathrm{i}}, \mathrm{t}_{\mathrm{j}}\right)-\widehat{\mathrm{S}}\left(\mathrm{x}_{\mathrm{i}}, \mathrm{t}_{\mathrm{j}}\right)\right)^{2} \\
\mathrm{~F}=\frac{1}{4}\left|\mathrm{~K}\left(\alpha, \delta, \mu, \mathrm{b}_{2}\right)+\mathrm{Q}\left(\alpha, \delta, \mu, \mathrm{b}_{2}\right)+\mathrm{R}\left(\alpha, \delta, \mu, \mathrm{b}_{2}\right)+\mathrm{S}\left(\alpha, \delta, \mu, \mathrm{b}_{2}\right)\right|
\end{array}\right\}
$$

where $\mathrm{n}$ and $\mathrm{m}$ exemplify the overall numbers of steps used in the solution area of and respectively, (K,Q, $\mathrm{R}$ and $\mathrm{S}$ ) the solution of nonlinear Ito coupled system (17)-(18)-(19)-(20), $\widehat{K}, \widehat{Q}, \widehat{R}$ and $\widehat{S}$ ) are the exact solutions for this system. (F) represents the fitness function (mean square error) is solved by using the (PSO). thus, the optimal values of system (17)-(18)-(19)-(20) are obtained through the next:

$$
\alpha=7, b_{2}=-8, \delta=-3, \mu=8
$$

The parameter settings used for the implementation of the algorithm are the default settings of the PSO code in the commercial software MATLAB ${ }^{\circ}$ R2017b, The Maple program was used to find the fitness function. When comparing the Nim numerical method and the (Nim) numerical method using the PSO algorithm with the numerical solution, we note the error is reduced to 10-23 at its lowest and up to 10-28 at its best as shown in Table 1 and Figures 2(a), 2(b), 3(a) and 3(b). When comparing the Nim numerical method and the (Nim) numerical method using the PSO algorithm with the numerical solution, we note the error is reduced to 10-27 at its lowest and up to 10-29 at its best as shown in Table 2 and Figures 4(a), 4(b), 5 (a) and 5(b). 
Table 1. Comparison of absolute error between the accurate solution and the numerical solution of (NIM)

\begin{tabular}{|c|c|c|c|c|}
\hline $\mathrm{t}$ & $\left|\boldsymbol{k}_{\text {exact }}-\boldsymbol{k}_{\text {nim }}\right|$ & $\left|\boldsymbol{k}_{\text {exact }}-\boldsymbol{k}_{\text {pso }}\right|$ & $\left|q_{\text {exact }}-q_{\text {nim }}\right|$ & $\left|q_{\text {exact }}-q_{\text {nim }(\text { pso })}\right|$ \\
\hline 0.1 & $2.209210^{*} * 10^{-5}$ & $1.037272 * 10^{-28}$ & $8.227572 * 10^{-4}$ & $5.311307 * 10^{-26}$ \\
\hline 0.2 & $4.312130 * 10^{-5}$ & $8.283629 * 10^{-28}$ & $9.315929 * 10^{-4}$ & $4.241265 * 10^{-25}$ \\
\hline 0.3 & $6.016000 * 10^{-6}$ & $2.794040 * 10^{-27}$ & $2.152349 * 10^{-4}$ & $1.430553 * 10^{-24}$ \\
\hline 0.4 & $1.961317 * 10^{-4}$ & $6.620901 * 10^{-27}$ & $3.159796 * 10^{-3}$ & $3.389906 * 10^{-24}$ \\
\hline 0.5 & $5.998332 * 10^{-4}$ & $1.292909 * 10^{-26}$ & $8.444311^{*} 10^{-3}$ & $6.619697 * 10^{-24}$ \\
\hline 0.6 & $1.291608 * 10^{-3}$ & $2.233874 * 10^{-26}$ & $1.661097 * 10^{-2}$ & $1.143744 * 10^{-23}$ \\
\hline 0.7 & $2.347910 * 10^{-3}$ & $3.547001 * 10^{-26}$ & $2.820174 * 10^{-2}$ & $1.816065 * 10^{-23}$ \\
\hline 0.8 & $3.847238 * 10^{-3}$ & $5.294302 * 10^{-26}$ & $4.375817 * 10^{-2}$ & $2.710683 * 10^{-23}$ \\
\hline 0.9 & $5.870208 * 10^{-3}$ & $7.537794 * 10^{-26}$ & $6.382119^{*} 10^{-2}$ & $3.859351 * 10^{-23}$ \\
\hline 1 & $8.499622 * 10^{-3}$ & $1.033949 * 10^{-25}$ & $8.893089 * 10^{-2}$ & $5.293819 * 10^{-23}$ \\
\hline
\end{tabular}

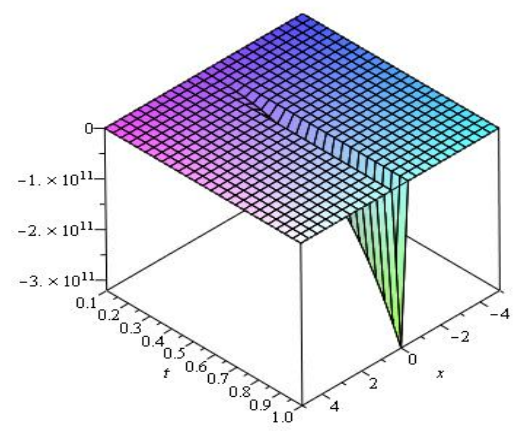

Figure 2(a). Numerical solution K3 using the pso algorithmusing the new iterative method

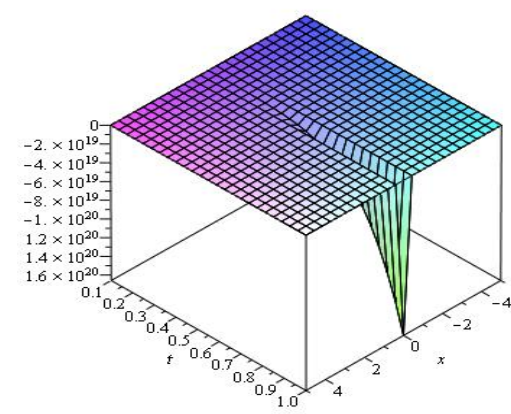

Figure 3(a). Numerical solution $\mathrm{Q}_{3} \mathrm{u}$ sing the new iterative method

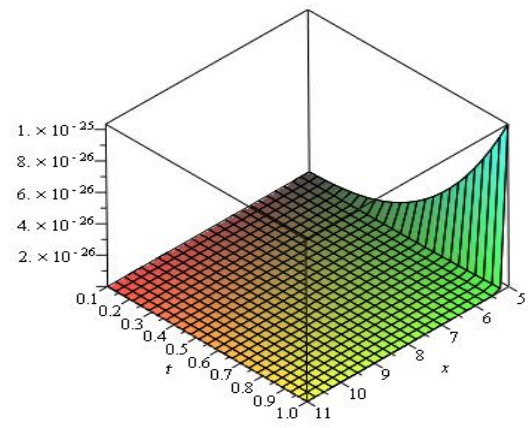

Figure 2(b). Absolute error K3 using the pso algorithm

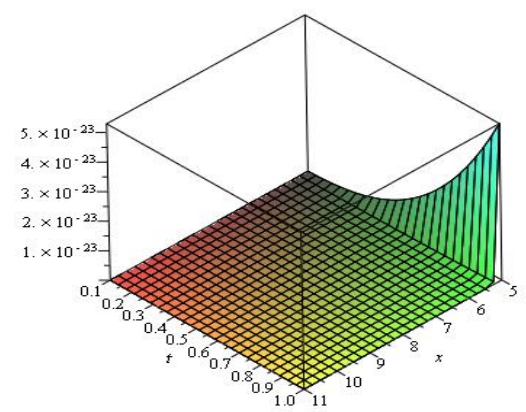

Figure 3(b). Absolute error $\mathrm{Q}_{3}$ using the pso algorithm

Table 2. Comparison of absolute error between the accurate solution and the numerical solution of the (NIM) technique and Pso

\begin{tabular}{ccccc}
\hline & $\left|\mathbf{R}_{\text {exact }}-\mathbf{R}_{\text {nim }}\right|$ & $\left|\mathbf{R}_{\text {exact }}-\mathbf{R}_{\text {nim }(\mathbf{p s o})}\right|$ & $\left|\mathbf{S}_{\text {exact }}-\mathbf{S}_{\text {nim }}\right|$ & $\left|\mathbf{S}_{\text {exact }}-\mathbf{S}_{\text {nim }(\mathbf{p s o})}\right|$ \\
\hline 0.1 & $9.810000 * 10^{-8}$ & $1.210920 * 10^{-29}$ & $9.810000 * 10^{-8}$ & $1.210920 * 10^{-29}$ \\
0.2 & $1.233300 * 10^{-6}$ & $4.843678 * 10^{-29}$ & $1.232700 * 10^{-6}$ & $4.843678 * 10^{-29}$ \\
0.3 & $5.747200 * 10^{-6}$ & $1.089828 * 10^{-28}$ & $5.746900 * 10^{-6}$ & $1.089828 * 10^{-28}$ \\
0.4 & $1.755420 * 10^{-5}$ & $1.937471 * 10^{-28}$ & $1.755340 * 10^{-5}$ & $1.937471 * 10^{-28}$ \\
0.5 & $4.230470 * 10^{-5}$ & $3.027299 * 10^{-28}$ & $4.230450 * 10^{-5}$ & $3.027299 * 10^{-28}$ \\
0.6 & $8.756040 * 10^{-5}$ & $4.359310^{*} 10^{-28}$ & $8.755970 * 10^{-5}$ & $4.359310^{*} 10^{-28}$ \\
0.7 & $1.629725 * 10^{-4}$ & $5.933506 * 10^{-28}$ & $1.629717 * 10^{-4}$ & $5.933506 * 10^{-28}$ \\
0.8 & $2.804784 * 10^{-4}$ & $7.749885 * 10^{-28}$ & $2.804783 * 10^{-4}$ & $7.749885 * 10^{-28}$ \\
0.9 & $4.544901 * 10^{-4}$ & $9.808449 * 10^{-28}$ & $4.544897 * 10^{-4}$ & $9.808449 * 10^{-28}$ \\
1 & $7.020970 * 10^{-4}$ & $1.210920 * 10^{-27}$ & $7.020964 * 10^{-4}$ & $1.210920 * 10^{-27}$ \\
\hline
\end{tabular}




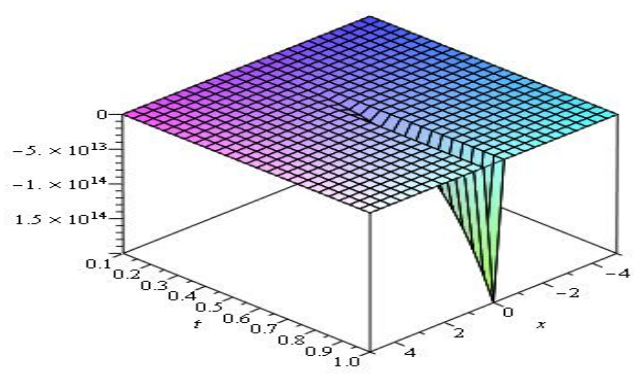

Figure 4(a). Numerical solution $\mathrm{R}_{3}$ using the new iterative method

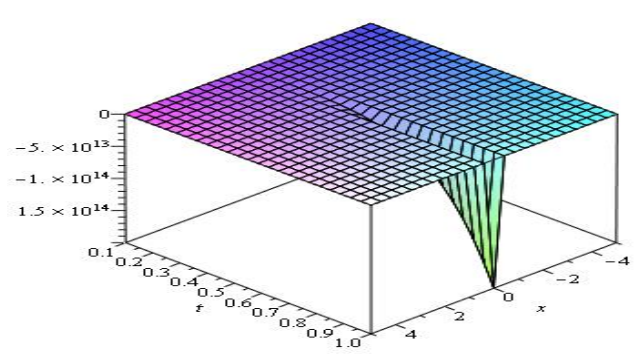

Figure 5(a). Numerical solution $S_{3}$ using the new iterative method

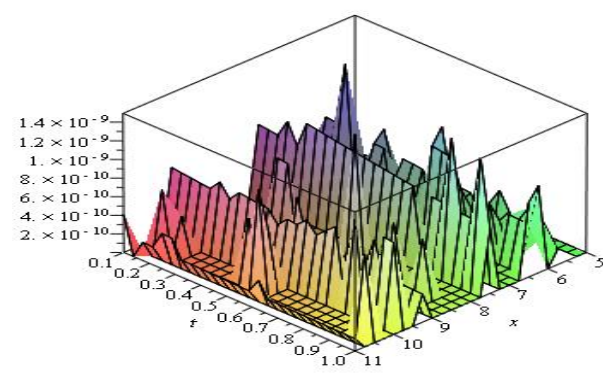

Figure 4(b). Absolute error $\mathrm{R}_{3}$ using the pso algorithm

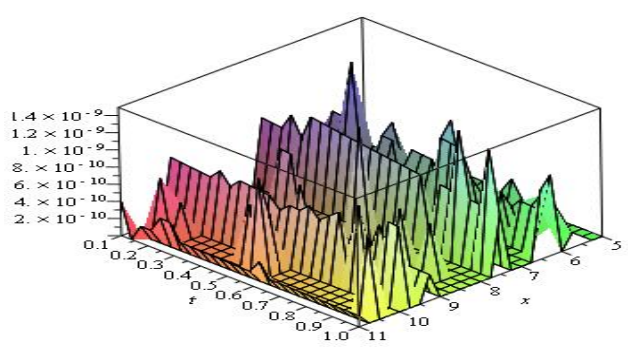

Figure 5(b). Absolute error $\mathrm{S}_{3}$ using the pso algorithm

\section{CONCLUSIONS}

In this paper, the nonlinear Ito system was solved by nim method with the PSO algorithm. The main idea was to search and then find the optimal parameters of Ito system $\left(\alpha, b_{2}, \mu, \delta\right)$, compared to the nim method in Tables 1 and 2. The optimum accuracy is very high although the Ito system is fairly complex and has many values and gives more accurate results than the NIM method. the numerical results showed that the approximate solutions obtained in the proposed method nim-pso were fully compatible with the exact solutions.

\section{ACKNOWLEDGMENTS}

The authors very grateful to the University of Mosul /College of Computer Sciences and Mathematics, for their provided facilities, which helped to improve the quality of this work.

\section{REFERENCES}

[1] Sunil Kumar, "A New Efficient Algorithm to Solve Non-Linear Fractional Ito Coupled System and Its Approximate Solution ", Applied Mathematics, 2014.

[2] A.M. Kawala, "Numerical Solutions for Ito Coupled System", Acta Applicandae Mathematica, 2009.

[3] Rajeswari Seshadri, Shankar Rao Munjam, "An Analytical Technique for Solving Simultaneous Strongly Nonlinear Equations-Application to Ito Coupled System", Proceedings of the UGC - Sponsored Two-Day National Seminar on Recent Developments in Functional Analysis, Topology and Graph Theory, p 33-40, 2015.

[4] M. Kawala, Hassan Zedan, "Application of variational iteration method for solving the nonlinear generalized Ito system", Journal of American Science, 2018.

[5] X. Zhao, H. Zhi and H. Zhang., "Improved Jacobi-function method with symbolic computation to construct new double periodic solutions for the generalized Ito system", Chaos Solitons Fractals, 28, 112-126 (2006).

[6] Zedan, H. A., \& Al-Aidrous, E., "Numerical solutions for a generalized Ito system by using Adomian decomposition method", International Journal of Mathematics and Computation, 4, 9-19 (2009).

[7] Alaidarous, E. S. A. "F-expansion method for the nonlinear generalized Ito system", International Journal of Basic \& Applied Sciences, 10 (2), 90-117 (2010).

[8] H. Zedan, W. Albarakati, and E. El-Adrous., "Comparisons between the solutions of the generalized Ito system by different methods", Life Sci. J., 10(1), 1512-1523 (2013). 
[9] Daftardar-Gejji and H. Jafari, “An iterative method for solving nonlinear functional equations," Journal of Mathematical Analysis and Applications, vol. 316, no. 2, pp. 753-763, 2006.

[10] A. Hemeda, "New iterative method: application to nth order integro-differential equations," International Mathematical Forum, vol. 7, no. 47, pp. 2317-2332, 2012.

[11] A. Hemeda, "Formulation and solution of $n$ th-order derivative fuzzy integrodifferential equation using new iterative method with a reliable algorithm," Journal of Applied Mathematics, vol. 2012, Article ID 325473, 17 pages, 2012.

[12] A. Hemeda, "New iterative method: application to the nth order integro-differential equations", Information B, Vol. 16, No. 6, pp. 3841-3852, 2013.

[13] Hemeda and M. Saleh Alluhaibi. "New iterative method for solving gas dynamic equation", International Journal of Applied Mathematical Research, 3(2):190-195, 2014.

[14] Ahmed Farooq Qasim, Badran Jasim Salim, "Application New Iterative Method for Solving Modified Korteweg-de Vries (MKdV) System from Three Equations", Jour of Adv Research in Dynamical \&Control Systems, Vol. 11, No. 3, 2019.

[15] AL-Azzawi S. F., Aziz M. M., "Chaos Synchronization of Nonlinear Dynamical Systems via a Novel Analytical Approach". Alexandria Engineering Journal. 2018; 57(4):3493-3500.

[16] Aziz M. M., AL-Azzawi S. F., “Anti-synchronization of Nonlinear Dynamical Systems Based on Gardano's method", Optik.2017; 134: 109-120.

[17] AL-Azzawi S.F. and Aziz M.M., "Strategies of Linear Feedback Control and its classification", Telkomnika (Telecommunication, Computing, Electronics and Control). 2019; 17(4):1931-1940.

[18] Al-Obeidi. A. S. AL-Azzawi. S. F. "Projective synchronization for a class of 6-D hyperchaotic Lorenz system". Indonesian Journal of Electrical Engineering and Computer Science (IJEECS). 2019;16(2):692-700.

[19] E. H. Doha, A. H. Bhrawy, and S. S. Ezz-Eldien, "A new Jacobi operational matrix: an application for solving fractional differential equations", Applied Mathematical Modelling, vol. 36, no. 10, pp. 4931-4943, 2012.

[20] Ghazanfari, A. G. Ghazanfari, and M. Fuladvand, "Modification of the homotopy perturbation method for numerical solution of nonlinear wave and system of nonlinear wave equations", The Journal of Mathematics and Computer Science, vol. 3, no. 2, pp. 212-224, 2011.

[21] Shivaji University, Kolhapur, Varsha Gejji, "New iterative method: Application to partial differential equations", Applied Mathematics and Computation, pp. 778-783, 2008.

[22] Mohammed Rasheed, Rosli Omar, Marizan Sulaiman, Wahidah Abd Halim, "Particle swarm optimisation (PSO) algorithm with reduced numberof switches in multilevel inverter (MLI)", Indonesian Journal of Electrical Engineering and Computer Science (IJEECS), Vol. 14, No. 3, June 2019, pp. 1114-1124.

[23] Mohammed Amine Meziane, Youssef Mouloudi, Bousmaha Bouchiba, abdellah Laoufi, "Impact of inertia weightstrategies in particle swarm optimization for solving economic dispatch problem", Indonesian Journal of Electrical Engineering and Computer Science (IJEECS), Vol. 13, No. 1, January 2019, pp. 377-383.

[24] Deepti Bala Mishra, Arup Abhinna Acharya, Rajashree Mishra, "Evolutionary algorithms for path coverage test data generation and optimization: a review", Indonesian Journal of Electrical Engineering and Computer Science (IJEECS), Vol. 15, No. 1, July 2019, pp. 504-510.

[25] Satyobroto Talukder, "Mathematical Modelling and Applications of Particle Swarm Optimization", Master Thesis, 2011.

[26] Al-Obeidi. A. S. AL-Azzawi. S. F. "Chaos synchronization in a 6-D hyperchaotic system with self-excited attractor". Telkomnika (Telecommunication, Computing, Electronics and Control, Accept on 2019-10-22.

[27] AL-Azzawi S.F., "Stability and Bifurcation of Pan Chaotic System by Using Routh-Hurwitz and Gardan method". Applied Mathematics and Computation. 2012; 219(3): 1144-1152.

[28] Dongshu Wang, Dapei Tan, Lei Liu, "Particle swarm optimization algorithm: an overview", Springer 22, pp. 387-408, 2018.

[29] Al-Thanoon, N.A., Qasim, O.S., Algamal, Z.Y., 2018. "Tuning parameter estimation in SCAD-support vector machine using firefly algorithm with application in gene selection and cancer classification”. Computers In Biology and Medicine, 103, 262-268. 